\title{
Paving New Roads To Knowledge: An Experiment To Enhance Construction Education
}

Anoop Sattineni, Auburn University

Steve Williams, Auburn University

\begin{abstract}
As a result of their own sometimes frustrating educational experiences, and a growing discontent with their current teaching methods, the authors, in conjunction with another instructor, decided to try an experiment. With the goal of enhancing visualization and understanding, the instructors created several multi-path educational paths for the reinforced concrete class. These alternative paths or "roads" included electronic visits to the site of the construction of a concrete frame building, homework assignments based on the various building components, discussions with the project manager, and a "hands on" public service project. This paper details the traditional and multi-path educational delivery models in a concrete course, resources required to "construct" more roads to knowledge, the results of a short survey of student reaction, and a synopsis of faculty comments on the effectiveness of the effort.
\end{abstract}

Keywords: Reinforced Concrete, Digital, Visualization, Simulation, Construction, Multimedia, Jobsite, Plans, Educational Delivery, Project Management.

\section{INTRODUCTION}

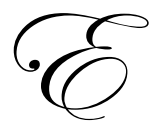

ducators have long agreed that the traditional lecture-based models of teaching are marginally effective (Haque, 2001). For efficient learning to take place, lectures should be supplemented by other techniques that actively engage students (Chickering and Gamson, 1991). Technological advancements during the past decade provide construction educators with opportunities to utilize other techniques to provide more effective learning environments and more pathways to the knowledge expected of the successful student.

Construction projects go through a phase in which the constructor must transform words and images (generally set forth in a two dimensional medium) into a functional three-dimensional entity. An intermediate and often difficult step in this process requires building a mental image of the project prior to the actual construction of the physical space. This ability to visualize generally improves as the constructor gains more experience.

Many construction students have limited construction experience and have difficulty visualizing and understanding building components or processes that are explained verbally and mathematically (Ryu et. al, 2003). Other construction educators have recognized this problem (Slattery 2000, Black and Duff 1994, Williams and Hein 1990). "The best laboratory for construction management is the construction project itself. There is no substitute for knowledge derived from a guided experience in the field." (Senior, 1998). Research shows that active learners are better able to understand complex material and apply that knowledge towards problem solving in a related context (Moore et. al, 2007). Realizing that any process that improves or facilitates visualization is arguably an enhancement to the educational process, construction educators have utilized field trips to enable students to better understand and visualize the concepts, procedures and processes described in the classroom. Unfortunately, there are many logistical problems associated with field trips to an actual construction site. Another drawback to the traditional field trip is that it only represents a snapshot in the history of the project. Consequently, students learn little about the sequencing and durations involved in the construction of the building. 
To alleviate some of the problems encountered on conventional field trips, construction educators have begun experimenting with electronic field trips. Different forms of the concept have been utilized for this evolving educational tool (Senior \& Miura 1997), (Ryan, 1998) and (Martz, 1999). This evolution and continued development is a result of the dynamic nature of the technology, strong industry interest in the electronic recording and archiving of construction documentation (Mills, 1999) and educational commitments from the construction industry.

The experiment described herein incorporates features of the electronic trips done by Ryan and Senior \& Miura and introduced new techniques for accessing information and acquiring knowledge. The construction of a hospital in Birmingham, Alabama, was used to illustrate the construction and design procedures. The 490,000 square foot poured in place three-story concrete frame included a variety of unique design features. Conventional resources used by professors include a set of building plans for each student in the class, a multimedia enabled classroom, and a conventional telephone. Digital resources included a project web site, digital photography, and digital video.

The reinforced concrete classes consist of approximately 30 students. Roughly half of the students major in construction management and half are architecture students. The course focuses on the principles involved in the design and construction of reinforced concrete elements (beams, columns and slabs) in typical buildings. Analytical reasoning and repetitive problem solving are important objectives for the course.

This paper discusses the process of creating supplementary ways to teach the subject matter, a comparison of the old and new educational delivery approaches, and the opinions of the participants involved in the experience.

\section{EDUCATIONAL DELIVERY MODELS}

Traditional Model: Figure 1 depicts the model traditionally used by engineering and construction educators for educational delivery of reinforced concrete course material.

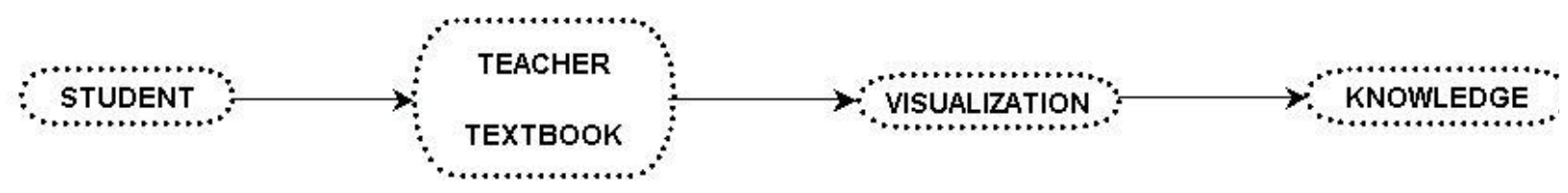

Figure 1: Traditional educational delivery model of the reinforced course.

In this model, the student relies solely on the teacher and/or the textbook in order to visualize and understand the concepts presented in class. The student is exposed to design problems and construction issues by both the teacher and the textbook. The student's knowledge of the material is evaluated by tests and homework.

Multi-Path Model: Due largely to a dissatisfaction with their experiences with the traditional educational model, the three instructors decided to try a new approach, depicted graphically in figure 2. The instructors discussed several questions that they felt should be explored during the course of the experiment.

1. Would a new approach help students visualize the construction better?

2. What technical issues would have to be resolved prior to changing the class?

3. How much additional time would be required on the part of the instructor?

4. Would the instructors still be able to cover the regular course objectives?

5. How much would the technical modifications cost?

6. Would the constructor (project manager) understand the needs of the teacher?

7. What incentives are required to persuade a project manager to participate? 


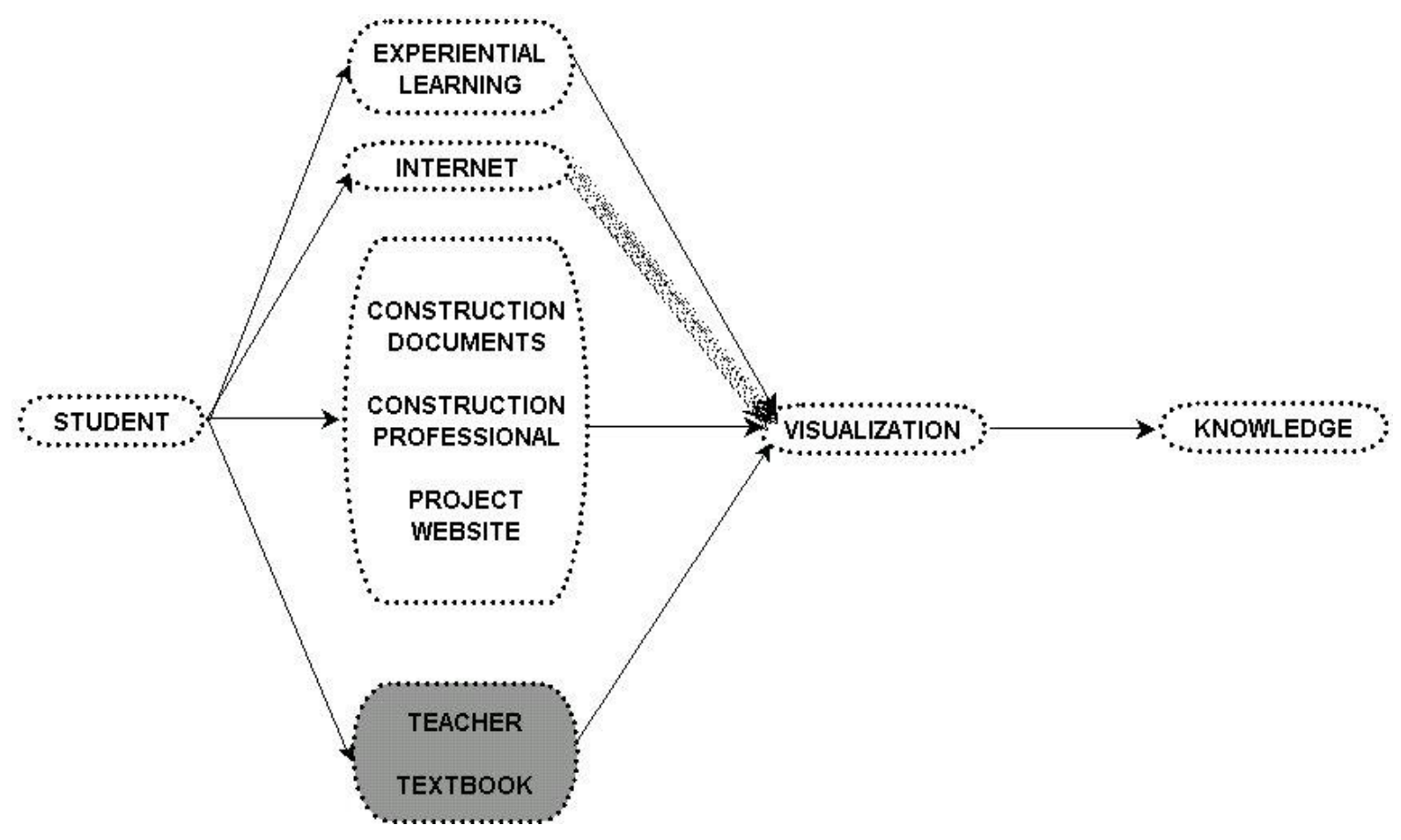

Figure 2: Multi-path educational delivery model of the reinforced course.

In the new model, all aspects of the traditional model are maintained and supplementary resources are added. Students are required to participate in a public service project. Working in groups of 4 or 5, they build a small concrete structure (slabs-on-grade, retaining wall, patio etc.,) for a charitable organization such as a church or school. The students are taken on virtual field trips where they examine digital images and digital video of an actual concrete building under construction. The virtual field trip is conducted four to five times during a semester and allows students to interact with construction professionals on the site via telephone. The students purchase a set of construction drawings associated with that building. A web site containing job related digital photographs and video allows students continuous access to information. In addition, a course website on blackboard has several links to topics on reinforced concrete technology on the internet.

The photographs and accompanying construction documents support the analytical portion of the course. Instead of using text-based problems, the actual structural elements of the concrete building toured in the virtual field trip are used for tests and homework assignments. A significant enhancement in this model is that the students are exposed to the design and construction of an entire structure, instead of the traditional series of unrelated components. This model enables the students to make the connection between the mathematical design simulation and the real building components.

A detailed discussion of the new components added to the traditional model and the resources used to accomplish them are described below.

\section{Service Learning}

The instructors felt that the best way to learn about placement and planning issues related to pouring concrete is by hands-on project that is a service to the community. Students build a small concrete structure (slabson-grade, retaining wall, patio etc.,) for a public organization (church, school, city projects, etc.). Each group is required to place six to twelve cubic concrete, depending on project requirements. The clients pay for the materials 
and the tools required, while the labor is donated. Students prepare a detailed proposal. They provide an estimate and schedule and work from a signed contract.

\section{Internet}

Several reputable concrete related websites posting educational information are available to students, faculty and construction professionals. These sites include the Portland Cement Association, the Pre-Stressed Concrete Institute, and the American Concrete Institute. The students' research issues specific to their public service project and write a referenced research paper. This procedure enhances the student's knowledge of concrete and exposes the students to on-line resources.

\section{Job Site Visit}

Two or three days prior to the 'virtual tour' the instructor selects ten to twenty images from the project website. The students are required to review the images prior to the "trip." Similarly, the project manager at the job site is notified of the images that have been selected, so that he can review them prior to the discussion.

On the day of the electronic visit, the project manager is called just prior to the beginning of class to insure the phone line is functioning properly. As class begins, the project manager is introduced via an amplified speakerphone. The project manager's image is captured with a small camera at the job site and is projected onto a large screen in the classroom. The project manager, via video-conferencing software, is likewise able to see the students, as their images are sent from a small camera in the classroom to his computer at the job site. The project manager and all students have a set of plans on their desks for reference.

The instructor adopts the role of moderator and displays various images and asks questions of the project manager. The project manager will frequently direct the class to a specific detail within the drawings and use the plans in conjunction with the electronic image to explain a particular component or process.

As the discussion progresses, students are drawn into the process. The project manager is able to recognize and accept questions from the students because he can see their raised hands on his camera. After the discussion is concluded, a review session is held. Issues and questions that cannot be resolved by the instructor are e-mailed to the project manager, and are typically answered within a day or two. The students are later tested on their knowledge and understanding of the discussion.

\section{RESOURCES}

The following resources were used to optimize the enhanced educational delivery. A detailed description of the resources follows the listing.

1. The construction site

2. The project manager

3. The students

4. The project website

5. Digital photography

6. Digital video

7. Architectural and structural drawings

8. Classroom Enhancements

9. Concrete materials

\section{Construction site:}

As mentioned earlier, the construction of a hospital, in Birmingham, Alabama was chosen to illustrate the construction procedures used to build a concrete structure. The 490,000 square foot poured in place three-story concrete building contained a significant amount of exposed architectural concrete, making the appearance of the 
concrete surface at the time of form removal a critical issue. Some of the more interesting elements in the structure included a 62' tall exterior concrete wall, an auditorium with a curved wall, extensive mock ups, and caissons placed on bedrock, and concrete block walls covered with a rubble stone facade.

\section{Project manager:}

The project manager was a willing and enthusiastic participant.

\section{Students:}

Each class was comprised of about 30 junior/senior students. The mix of students varies, but roughly half were studying architecture and half were studying construction management. Since the aesthetic quality of the concrete is an architectural issue, the mix of architectural and construction students often proved a spark for many discussions.

\section{Project website:}

A website for the project was developed by the project manager to allow the owner to view job progress without traveling to the site. This same site turned out to work well in the classroom. The site was maintained by the project manager and updated two to three times a week. A typical screen shot of the website is shown in figure 3.

The website was organized in three frames. The dates were located in the bottom left hand corner, a list of the pictures taken on a particular day on the right hand of the screen and the digital images on the top left hand corner of the screen. This organization allowed the users to access all the digital images and monitor the progress of work from the same page. This organization of the website was helpful since on any given day, the project manager and the class would be looking at the same page.

\section{Digital photography:}

The project manager took digital photographs at every stage of construction. The digital photographs were arranged in a manner such that they documented the construction of a typical element from start to finish. An example of one of these images is shown in figure 4 .

In a typical class session, the instructor might start the conversation by asking the project manager about the formwork in the photograph in figure 4. After an appropriate response, the project manager might direct the students to the location of a particular structural element in the plans and then suggest that the instructor look at other images that might document a continuation of the process.

\section{Digital video:}

A digital video camera was used to document the activities where student understanding was enhanced by motion. The project manager quickly learned to use the recorder, but was disappointed that so much time was required to edit them. The digital video clips were not placed on the web site as they consumed large amounts of digital storage. The clips were instead sent to the University and placed on network drives, so that all students had access to them. In a typical classroom session, the students and the project manager could look at the same video clip on their respective computers. The project manager could then explain the sequence of events shown in the video. 


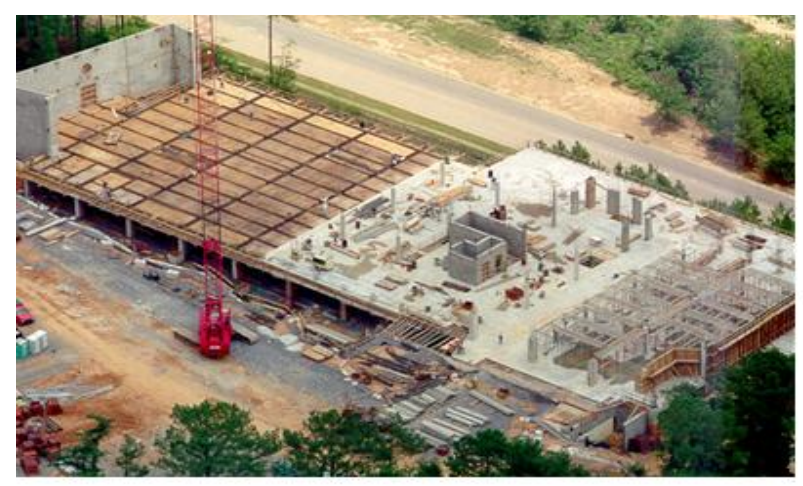

\begin{tabular}{|l|l|}
\hline Picture & Description 6-98 \\
\hline General Note: & Pictures were taken mid-June 1998. \\
\hline North view.jpg & North aerial view of jobsite. \\
\hline South view.jpg & \\
\hline West view.jpg & \\
\hline
\end{tabular}

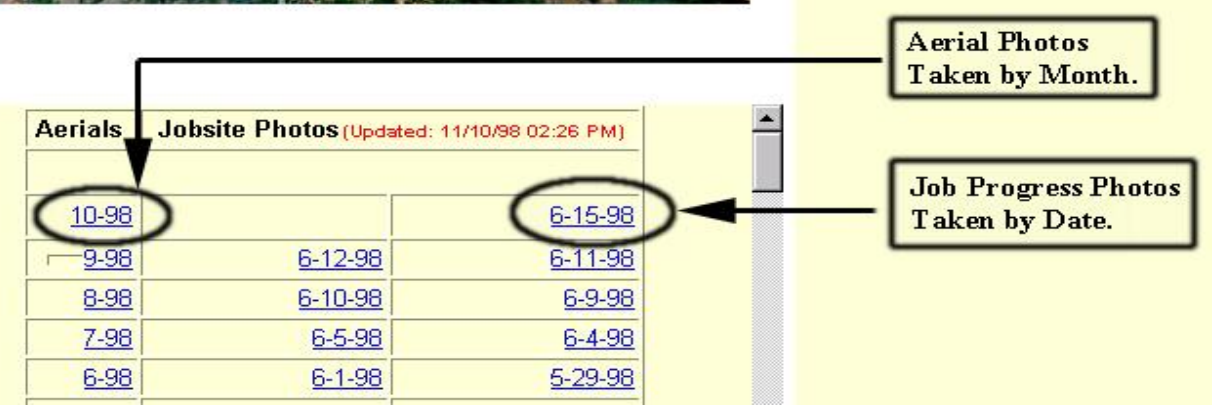

Figure 3: Typical screen shot of the project website.

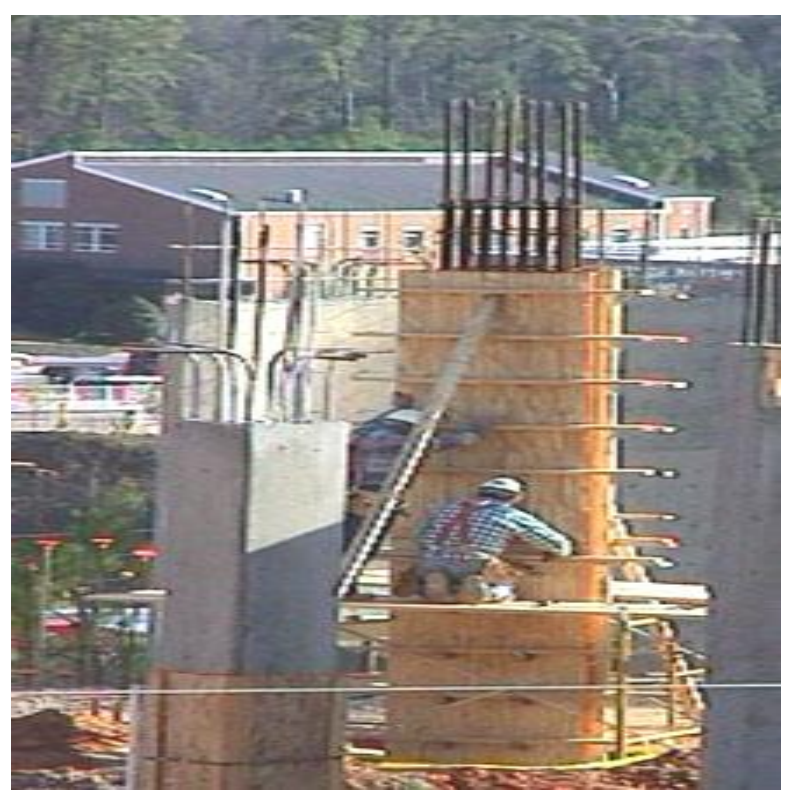

Figure 4: Digital Photograph of Formwork. 


\section{Plans:}

A set of 15"x 24" plans of the hospital project was given to each student. These plans consisted of drawings deemed most important and were not a complete set. They included 19 architectural drawings, 5 foundation drawings and 17 structural drawings. Sixty sets of plans were duplicated and each student was given a set of plans at the beginning of the course. The plans also served as a source for design problems. The instructors would assign students analytical problems from the plans. Students could then compare their solutions and designs with those of the real structural engineer. The project manager also emphasized the importance of the plans and made frequent reference to them in his discussions.

\section{Classroom Enhancements:}

A conventional telephone was used to communicate with the project manager on the job site. This device was set up so that the verbal conversation between the project manager and the instructor went through the main sound system of the classroom. The clarity of a conventional dedicated telephone line was found to be more dependable than the net meeting Internet software, which was sometimes unreliable due to heavy network traffic. Internet based conferencing software was used, primarily to maintain video transmission between the project manager and the students. The project manager also occasionally used the software to show the students some of the equipment used on the job site. Although the video quality was marginal, being able to see the project manager seemed to help engage the students. The projection device has the capability of producing a resolution of $1024 \times 768$. The size of the entire image was about eight feet square, and clearly visible to all students in the classroom.

\section{Concrete materials:}

The clients provided the materials and tools required for the public service project. The students, in turn, provided the labor and were guided by the instructor.

\section{STUDENT RESPONSE TO THE ELECTRONIC FIELD TRIP}

A survey of the students was conducted at the end of each course. A total of 82 students responded, and the results were recorded. The questionnaire was not designed to be statistically relevant, and is intended to serve only as anecdotal documentation. The students were asked to rate the following statements on a scale of 1 to 5 , using 1 to indicate 'strongly disagree' and 5 for 'strongly agree'. The statements are listed below and the student responses are summarized in figure 5 and figure 6.

As noticed in the charts shown in figure 5 and figure 6 (following), the general response from the students was very positive. However a few students were less enthusiastic about the electronic field. Each student was also asked to give written comments about the electronic field trip. A sampling of the student comments is listed below.

1. The electronic field trip was a great way to learn about the concrete pouring processes without actually being at the site. Many of the concepts illustrated in the pictures served as valuable resources for the final project; also, by not having any concrete experience whatsoever, the "field trips" helped me to visualize the many tasks which help to create a successful pour. The only thing that I would consider would be to show less pictures during each class, thus increasing the amount of field trips \& help in the learning process.

2. I think the electronic field trip is a great learning tool for people that have not spent much time on construction sites. Personally, I had already seen most of the things we discussed, through co-op. So I don't think I got as much out of it as others did. I wish we could have gone further into the job and discussed elevated slabs and second floor columns.

3. I found it very helpful and interesting. It's usually very hard to get a clear picture of what we are learning, but the field trip helped. 4 or 5 classes is a pretty good amount.

4. I honestly believe there is no comparison to hands on experience, and this electronic field trip is about as close as you can get in the class room. This is a very effective means of teaching and should be done in other classes as well. 
5. I'm not sure why, the electronic field trip didn't stimulate my thinking, as much as it seems like something that difficult and expensive would. I think the technology may have been a little distracting (especially when it failed or when it was interrupted).

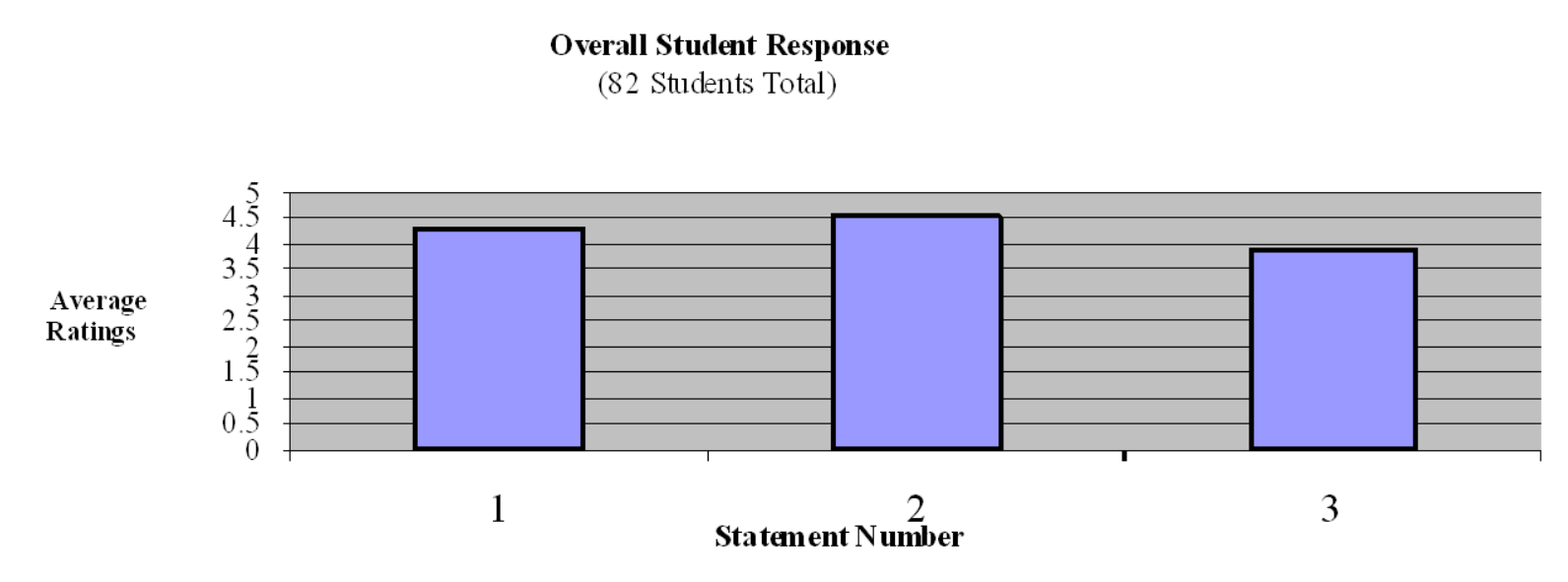

Statements:

1. The electronic field trip component of this course is effective as an educational tool.

2. The electronic field trip should be maintained in future concrete courses.

3. I feel my knowledge of field construction techniques was significantly enhanced as a result of the electronic field trip.

Rating Criteria: '1' for "Strongly Disagree" and '5' for "Strongly Agree”.

Figure 5: Average Student responses to the statements above, for all instructors.

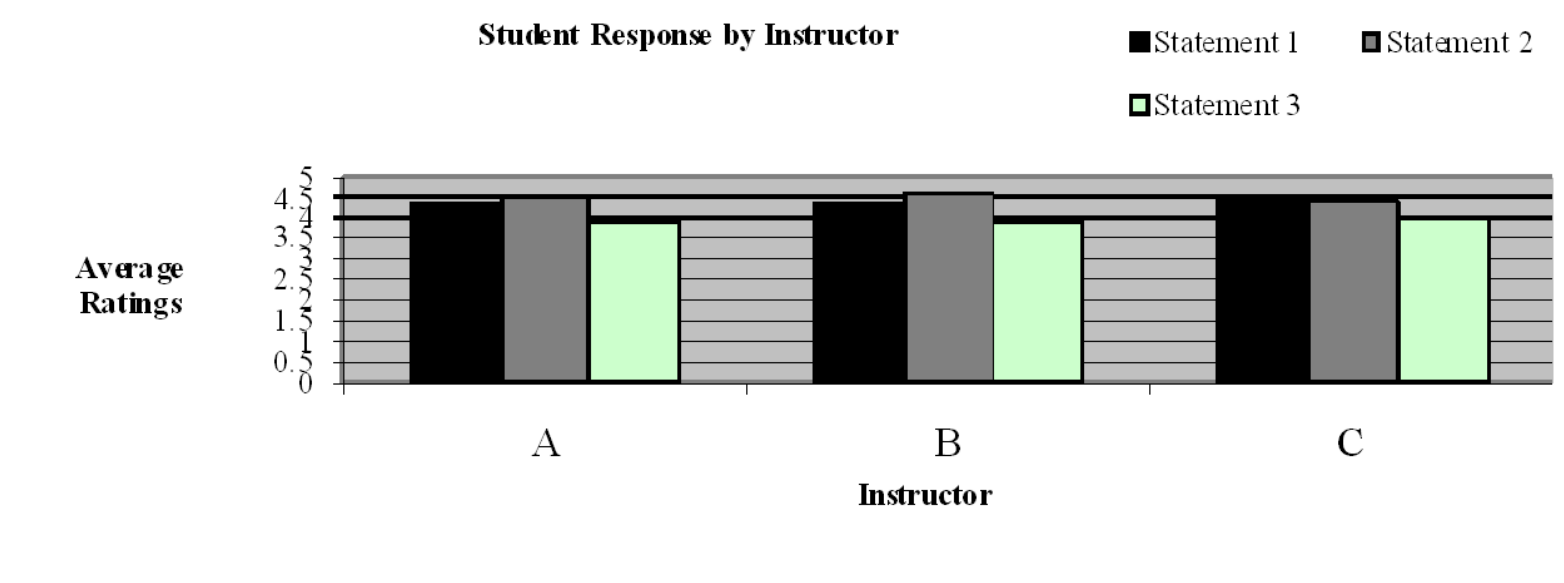

Statements:

1. The electronic field trip component of this course is effective as an educational tool.

2. The electronic field trip should be maintained in future 314 courses.

3. I feel my knowledge of field construction techniques was significantly enhanced as a result of the electronic field trip.

Rating Criteria: '1' for "Strongly Disagree" and '5' for "Strongly Agree”.

Figure 6: Student responses to the above statements, by instructor. 


\section{CONCLUSIONS AND OBSERVATIONS}

After four sections of the reinforced concrete class had been taught using the multi-path educational delivery model, the three instructors met for a post project review. The questionnaires, along with the comments from the 82 students taking the classes were placed into a database and reviewed. Each instructor shared his thoughts on the effectiveness of the new format. The opinions of the three instructors were very consistent. The results of the review and the observations of the instructors are summarized below.

1. While the effectiveness of the multi-path approach is not quantifiable (i.e. learning was increased by $37 \%$ ), the opinions of both the students and the instructors indicated strong enthusiasm for the enhanced educational model.

2. Presentation of the material in various forms of media enhanced student understanding and visualization of the processes. During the review process one of the instructors made the following statement. "When I was in college I had three courses dealing with the design of reinforced concrete, and I never saw a set of plans or a real building under construction." This comment sparked a discussion about visualization, and another instructor said, "Our students are now exposed to the instructor's words and sketches, they are exposed to digital images coupled with verbal explanations from the project manager, and they work with drawings of the structure done by the structural engineer and the architect. At the end of the course they actually construct a concrete slab on grade. As a teacher I know the learning environment is improved." All three instructors agreed that the student comments supported this statement.

3. The students and the instructors expressed a strong sentiment that electronic field trips should be retained as an integral part of the course.

4. An unanticipated benefit was that all three instructors became students when the project manager was briefing the class. All three instructors learned new things about reinforced concrete construction. As an example, all instructors gained new insight about the contractual interaction between the contractor and the architect regarding the use of "mock-ups" in the process of producing architecturally acceptable finished wall surfaces.

5. The multi-path model demands more time of the instructor. In the beginning the instructors spent considerable time planning the classes and testing the technology. The effort required diminished as the instructors became more proficient, but remained significant. However, based on the responses of the students, the instructors felt that the benefits of the multi-path approach far outweigh the negative aspect of additional time requirements, and remain committed to the new approach.

6. All three instructors plan to incorporate facets of the enhanced educational delivery model in other classes.

7. The instructors realized that the role of the constructional professional was very crucial in the success of this experiment. In this case, the project manager was very enthusiastic and committed to the success of the experiment. In addition, he possessed excellent communication skills and related well to the students.

8. Student response to the experiential learning aspect of the course was overwhelmingly positive. Students seemed very proud of the projects they had constructed for the community and often took parents and friends to see them. The city school board has formally recognized the department for their contribution

9. The instructors were at first concerned about the need to provide incentives for the industry partners to participate in this experiment. After discussing this issue with several contractors, this concern appears to be unnecessary as several more industry partners have expressed interest in participating in classes of this nature. endeavors.

The authors hope that their experiences will help other construction educators in pursuing similar

\section{REFERENCES}

1. Black R. G. and Duff S. (1994), A Model for Teaching Structures: Finite Element Analysis in Architectural Education, Journal Architectural Education, Vol. 48, Issue 1 - September 1994

2. Chickering A.W. and Gamson Z.F. (1987) 7 Principles for Good Practice in Undergraduate Education, The Wingspread Journal, June 1987 
3. Chickering A.W. and Gamson, Z.F. (1991) New Directions for Teaching and Learning, Applying the Seven Principles for Good Practice in Undergraduate Education, Compiled in a study supported by the American Association for Higher Education, the Education Commission of the States, and The Johnson Foundation. Editors, Jossy-Bass, 1991.

4. Haque M.E (2001), Web Based Visualization Techniques for Structural Design Education, 2001 ASEE Annual Conference \& Exposition

5. Martz B. (1999), A Three-way Partnership for Learning: On-Campus Electronic Internships, Technological Horizons in Education, December 1999, 34-40.

6. Mills T. (1999), REDLINE - Real-time Documentation Linking Images and Notations Electronically, Journal of Construction Education, Vol. III, No. 1, 87-95.

7. Moore A. H, Fowler S.B and Watson C.E., Active Learning and Technology: Designing Changes for Faculty, Students and Institutions, Educasue Review, September/October (2007)

8. Ryan R. (1998), The Use of Nonlinear Computerized Presentation to Simulate a Practical Experience, Journal of Construction Education, Vol. 2, No.3, 218-226.

9. Ryu, S; Kim, M H; Kinnas, S A; Kang, J H, Development of Web-based Numerical Wave Tank and Java Applets as an Advanced Tool for Teaching Wave Mechanics, 2003 ASEE Annual Conference \& Exposition.

10. Senior B. (1998), Infusing Practical Components Into Construction Education, Journal of Construction Education, Vol. 2, No. 3, 145-154.

11. Senior B. \& Miura A., (1997), Developing an Educational Interactive Multimedia Application for Construction Estimating, Journal of Construction Education, Vol. 1, No. 2, 93-101.

12. Slattery T. K. (2000), Design by Analysis Tool for Teaching Formwork Design, ASC Proceedings.

13. Williams S. and Hein M. (1990), Rethinking the Structures Curriculum, ASC Proceedings. 